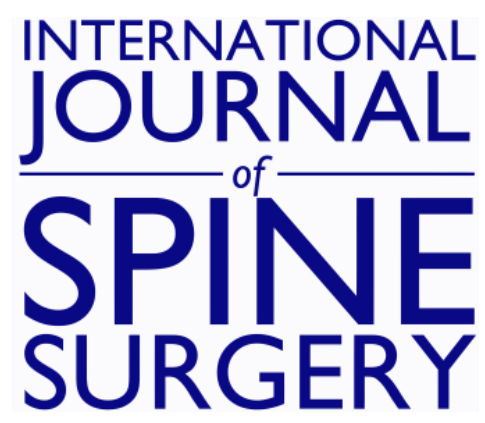

\title{
Outcome Analysis of Subaxial Cervical Spine Tuberculosis Operated by the Anterior Approach: A Single-Center Experience
}

Sudhir Srivastava, Kunal Roy, Sunil Bhosale, Nandan Marathe, Aditya Raj and Rishi Agarwal

Int J Spine Surg 2021, 15 (1) 18-25

doi: https://doi.org/10.14444/8002

http://ijssurgery.com/content/15/1/18

This information is current as of April 26, 2023.

Email Alerts Receive free email-alerts when new articles cite this article. Sign up at:

http://ijssurgery.com/alerts

The International Journal of Spine Surgery

2397 Waterbury Circle, Suite 1,

Aurora, IL 60504, Phone: +1-630-375-1432 


\title{
Outcome Analysis of Subaxial Cervical Spine Tuberculosis Operated by the Anterior Approach: A Single-Center Experience
}

\author{
SUDHIR SRIVASTAVA, MS (ORTHO), KUNAL ROY, MS (ORTHO), SUNIL BHOSALE, MS (ORTHO), \\ NANDAN MARATHE, MS (ORTHO), ADITYA RAJ, MS (ORTHO), RISHI AGARWAL, MS (ORTHO) \\ Department of Orthopedics, Seth GS Medical College and KEM Hospital, Mumbai, Maharashtra, India
}

\begin{abstract}
Background: Though spinal tuberculosis has a predilection for the dorsal and lumbar spine, a high percentage of morbidity and mortality is associated with cervical tuberculosis. Cervical tuberculosis accounts for about $10 \%$ of cases, with the major concerns being quadriparesis/quadriplegia and kyphotic deformity. Herein we describe our experience with the use of anterior instrumentation with titanium implants in 46 patients with subaxial tuberculosis.

Materials and Methods: Included in the study were a total of 46 patients with subaxial cervical (C3-C7) and upper dorsal (D1-D3) tuberculosis who underwent operations with anterior debridement, decompression, bone grafting, and anterior instrumentation by a single surgeon at our institute between January 2007 and December 2014. A review of the demographic data, medical records, and x-rays before and after surgery and at subsequent follow-ups was performed retrospectively from the departmental database.

Results: Neurological involvement in the postoperative period was seen in 29 of the 30 patients, 26 of whom showed complete neurological recovery. The Cobb angle at presentation ranged from $2^{\circ}-58^{\circ}$ of kyphosis with an average kyphosis of $15.4^{\circ}$. The average lordosis after surgery was found to be $17.5^{\circ}$ (ie, a mean correction of $32.9^{\circ}$ ).

Conclusions: Anterior instrumentation of subaxial cervical tuberculosis with titanium implants provides good correction of kyphosis and provides reasonable neurologic recovery in patients and ensures a long-lasting functional outcome.

Level of evidence: 4.
\end{abstract}

Cervical Spine

Keywords: tuberculosis, subaxial cervical spine, anterior cervical instrumentation

\section{INTRODUCTION}

Tuberculosis (TB) of the spine is one of the oldest demonstrated diseases known to humans. Evidence dates back as early as the Egyptian mummies with spinal tuberculosis discovered in $4000 \mathrm{BC}$. The classical description of spinal tuberculosis was first presented by Sir Percival Pott ${ }^{1}$ in 1779 ; hence, it is also known as Pott spine. Spinal tuberculosis is the most commonly encountered form of extrapulmonary $\mathrm{TB}$, accounting for approximately half of all cases of musculoskeletal TB. ${ }^{2}$ Though spine TB has a predilection for the dorsal and lumbar spine, a high percentage of morbidity and mortality is associated with cervical tuberculosis.

Cervical TB accounts for about $10 \%$ of cases, with the major concerns being quadriparesis/quadriplegia and kyphotic deformity. ${ }^{3}$ Along with antitubercular chemotherapy, surgical decompres- sion of the neural tissue and correction of deformity with implants has been well described for thoracic and lumbar spine. ${ }^{4}$ Here we describe our experience with the use of anterior instrumentation with titanium implants ${ }^{5}$ in 46 patients with subaxial cervical spine TB.

\section{MATERIALS AND METHODS}

Included in the study were a total of 46 patients with subaxial cervical (C3-C7) and upper dorsal (D1-D3) TB who underwent operations with anterior debridement, decompression, bone grafting, and anterior instrumentation by a single surgeon at our institute between January 2012 and December 2017. A review of the demographic data, medical records, and x-rays before and after surgery and at subsequent follow-ups was performed retrospectively from the departmental database. 
The microbiological diagnosis was made with the help of liquid culture by mycobacterial growth indicator tube (MGIT), cartridge-based nucleic acid amplification technique (Gene Xpert -Cepheid, California), and histopathology. Patients with either a positive report on MGIT or Gene Xpert in combination with a corroborative histopathological diagnosis were included. Among the patients with a positive growth on MGIT, only those with growth for Mycobacterium tuberculosis were included in the study. Patients with atypical mycobacteria growth were excluded from the study. Patients with upper cervical tuberculosis, involvement of posterior elements, and skip lesions in other cervical regions were excluded. In addition, patients undergoing a repeat surgery for cervical tuberculosis were not included in the study. Neurology was assessed by the Frankel grading system ${ }^{6}$ and pain was graded using a 10-point visual analog score. The indication for surgery was to relieve pain, improve neurological impairment, and prevent or correct spinal deformity.

Preoperative radiographs included an anteroposterior view and lateral view of the cervical spine. Preoperative MRI were done in all patients. ${ }^{7}$ An anteroposterior view and lateral radiograph of cervical spine was done postoperatively and during follow-up at 3, 4.5, 6, 9, and 12 months and yearly after that. Angle of kyphosis ( $\mathrm{K}$ angle) was calculated using Osirix MD (Pixmeo, Geneva, Switzerland) by drawing lines from the upper border of the first normal vertebra above and the lower border of the first normal vertebra below the diseased area using dynamic angles. A computed tomography (CT) scan was done at 12 months to assess bony fusion if not evident on plain radiographs. Anterior fusion was assessed by the presence of bridging bone between the vertebrae immediately proximal and distal to the reconstructed area. The first author (S.S.), who is also the lead surgeon for all the cases, assessed fusion.

\section{RESULTS}

Mean age of the patients was 37.4 years and ages ranged from 7 years to 65 years, though there was only 1 patient younger than 20 years. The mean duration of symptoms before presentation was 6.2 weeks (2-9 weeks). Eleven patients also were diagnosed with concomitant nonosseous tuberculosis, with 3 patients having abdominal Koch disease, and 4 each having pleural effusion and pulmonary
Table 1. Age distribution.

\begin{tabular}{lc}
\hline Age Groups, $\mathbf{y}$ & No. of Patients \\
\hline$<20$ & 1 \\
$21-30$ & 16 \\
$31-40$ & 10 \\
$41-50$ & 5 \\
$51-60$ & 10 \\
$>60$ & 4 \\
Total & 46 \\
\hline
\end{tabular}

tuberculosis. Neck pain and stiffness was present in all the patients, with only 29 patients having constitutional symptoms such as evening rise of temperature, loss of appetite, and loss of weight. Neurological status was Frankel grade E in 16 patients, D in 10, $\mathrm{C}$ in 19, and a further 1 had Frankel grade A neurology.

All surgeries were performed at the same institute by a single operating surgeon. Of a total of 46 patients included in the series, 21 were females and 25 males. There was 1 patient in the pediatric age group. Age of the adult patients ranged from 21 to 65 years. Agewise distribution is shown in Table 1. The predominantly involved level was fifth and sixth cervical vertebrae seen in 21 patients. Only 2 patients had affection of the D1-D2 levels. The distribution of various levels of decompression and the patient distribution are shown in Table 2. There was 1 patient, a 46-year-old man, who had a positive history of being affected by HIV and had been on antiretroviral therapy for 6 years. ${ }^{8}$ Extraosseous tuberculosis ${ }^{9}$ was seen in 11 patients, of whom 3 had abdominal tuberculosis and 4 each were affected by pulmonary tuberculosis and tubercular pleural effusion. Neurological involvement with Frankel grade $\mathrm{C}$ at presentation was seen in 19 of the 46 patients. Of these, 16 patients showed complete neurological recovery with grade $\mathrm{E}$ neurology according to the Frankel grading system at final follow-up. The remaining 3 recovered to a Frankel grade D. All the patients with Frankel grade D at presentation showed improvement in their neurological status at the time of final follow up. All

Table 2. Level of decompression with the distribution of patients.

\begin{tabular}{lc}
\hline Level of Decompression & No. of Patients \\
\hline C3-C4 & 2 \\
C4-C5 & 8 \\
C5 only (single level) & 1 \\
C5-C6 & 24 \\
C5-C6-C7 & 2 \\
C6-C7 & 5 \\
D1-D2 & 4 \\
Total & 46 \\
\hline
\end{tabular}




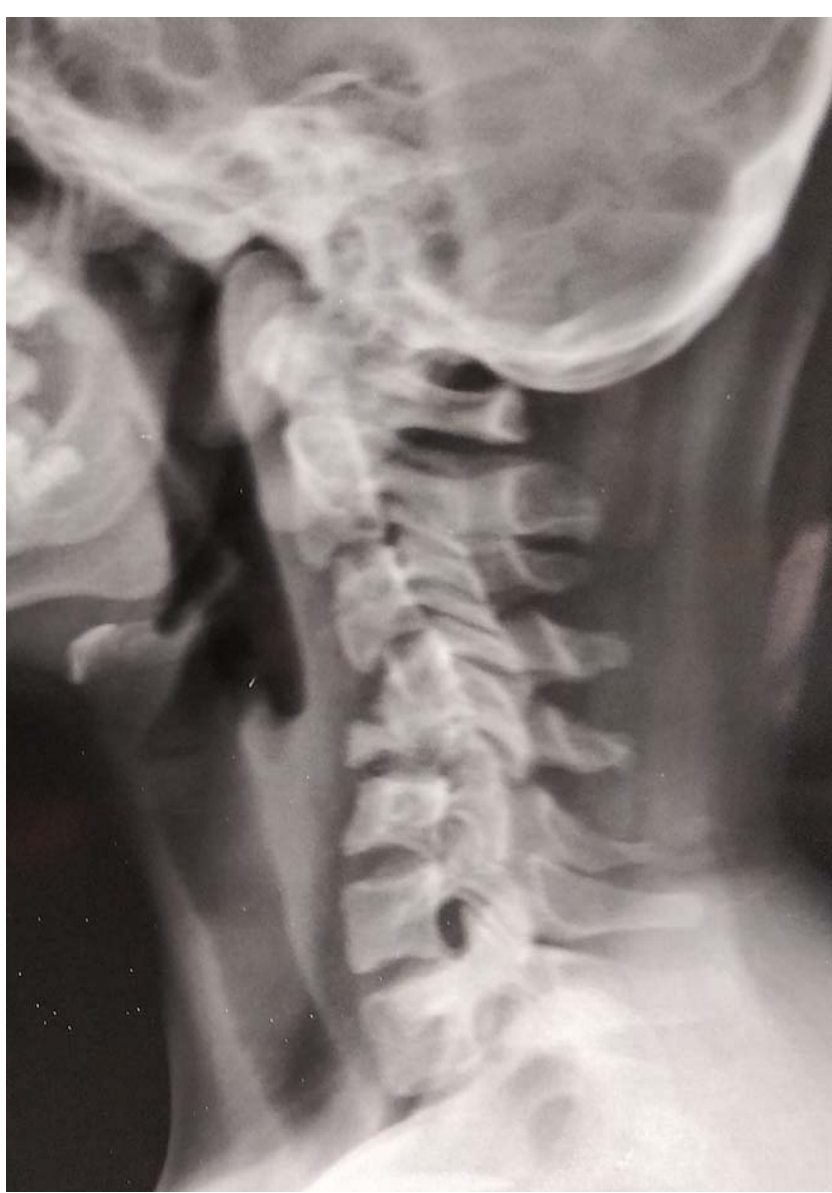

Figure 1. Plain lateral radiograph of a 24-year-old woman with C4-C5 tuberculosis and $30.6^{\circ}$ kyphosis in the subaxial cervical spine.

patients with Frankel grade E continued to have the same grading in the postoperative period and at final follow-up. There was only 1 patient with Frankel grade A at presentation that improved to grade $\mathrm{C}$ within 6 months postsurgery.

The Cobb angle at presentation ranged from $2^{\circ}-$ $58^{\circ}$ of kyphosis with an average kyphosis of $15.4^{\circ}$. The average lordosis after surgery was found to be $17.5^{\circ}$ (ie, a mean correction of $32.9^{\circ}$ ). The maximum correction was achieved in a 35-year-old woman with tubercular involvement of C5-C6 vertebrae, where a preoperative kyphosis of $58^{\circ}$ was corrected to $6^{\circ}$ of lordosis in the postoperative period. An average loss of $2.6^{\circ}$ of lordosis was seen at final follow-up in the series. Time to union as assessed by $\mathrm{x}$-ray and CT scan (if required) ranged from 3-9 months, with an average of 5.59 months. Three patients complained of temporary dysphagia lasting for an average of 3 weeks postsurgery but that later resolved without any additional intervention. One patient had superficial wound dehiscence at the graft site that healed by daily dressing. Another patient

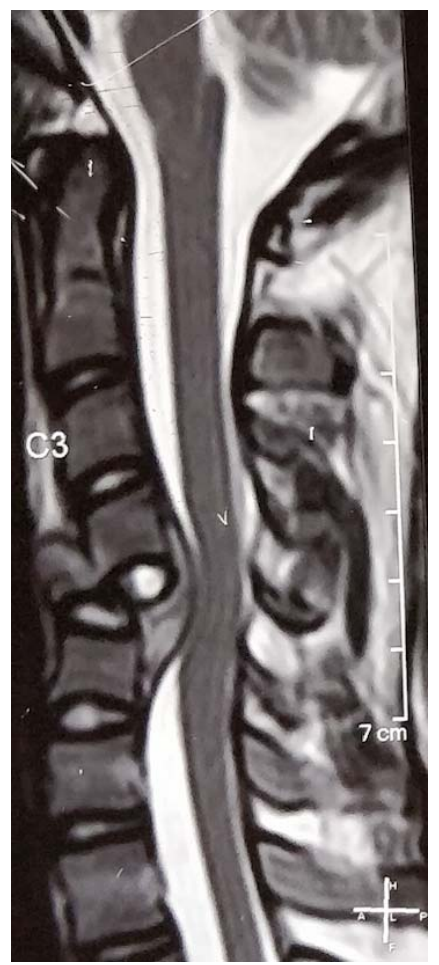

Figure 2. T2-weighted sagittal MRI depicting extensive vertebral body destruction and abscess causing compression of the spinal cord.

had an implant loosening 32 months after surgery and required implant removal. There was solid anterior fusion in this patient, and hence no additional augmentation was done.

\section{Case Illustration 1}

A 24-year-old woman presented with neck pain and gradually progressive weakness of all 4 limbs (Frankel C) for 2 months. After radiological investigations, she was suspected to have a C4-C5 spondylodiscitis and $30.6^{\circ}$ kyphosis in the subaxial cervical spine at presentation (Figure 1). T2weighted sagittal MRI was suggestive of extensive vertebral body destruction and epidural abscess causing compression of the spinal cord (Figure 2). She was started on antituberculous chemotherapy and later planned for surgical intervention. Anterior debridement, tricortical iliac crest bone grafting, and instrumentation with plate was carried out (Figure 3). She recovered to Frankel grade E and showed good anterior fusion by 12 months postsurgery (Figure 4).

\section{Case Illustration 2}

A 34-year-old woman presented with a 6-month history of neck pain, radiculopathy, and weakness 


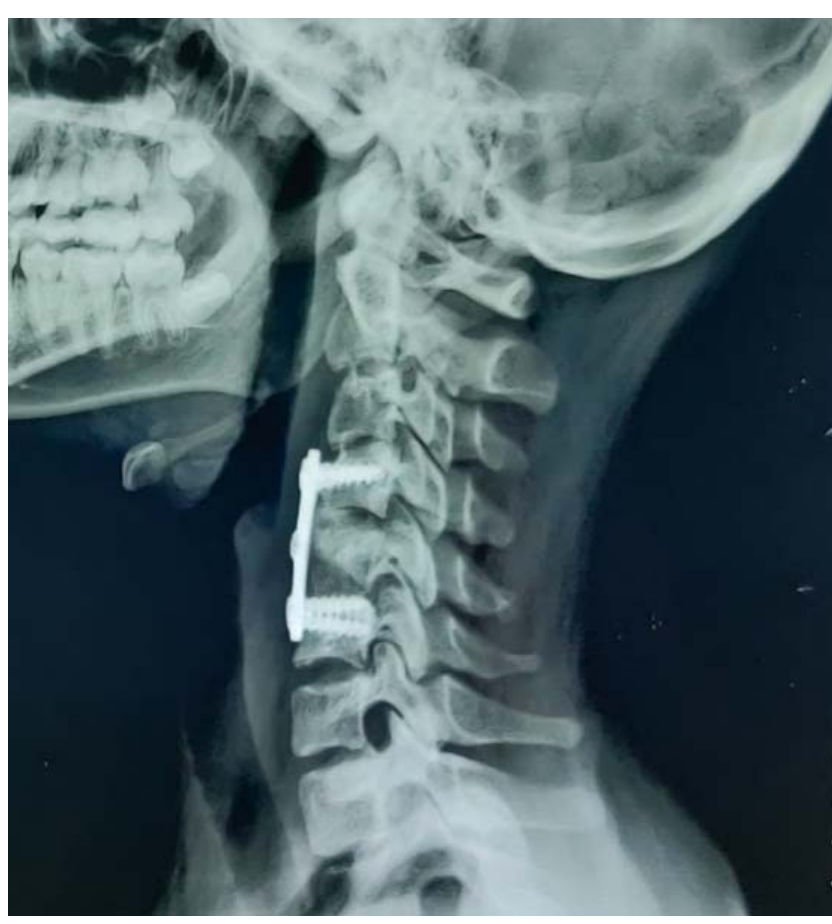

Figure 3. Postoperative plain lateral radiograph demonstrating correction of cervical alignment to lordosis, anterior instrumentation with a plate, and reconstruction with tricortical autologous bone graft.

of lower limbs. She was ambulatory at presentation. Plain radiographs revealed destruction of $\mathrm{C} 5$ and C6 vertebral bodies (Figure 5A). T2 sagittal MRI demonstrated retropulsion of $\mathrm{C} 5$ and compression of spinal cord (Figure 5B). T2 axial MRI showed severe ventral compression of cord with loss of cerebrospinal fluid signal (Figure 5C). The patient also had a skip lesion at D11-D12 with no cord compression (Figure 5D). She underwent anterior surgery with debridement, bone grafting, and anterior plating (Figure 5E and 5F). She recovered to Frankel grade $\mathrm{E}$ at the time of final follow-up.

\section{Case Illustration 3}

A 40-year-old woman presented with neck pain and imbalance during walking for 3 weeks. Neurologically she had no loss of motor power but did have hyperreflexia and spasticity in all 4 limbs. Radiological investigations revealed destruction of $\mathrm{C} 3$ and $\mathrm{C} 4$ with cord compression (Figure 6A-6D). The patient was started on antitubercular chemotherapy and underwent surgical decompression and stabilization by anterior approach. Anterior column reconstruction was done by iliac crest autograft (Figure 6E). The patient remained neurologically intact at final follow-up and demonstrated solid bony fusion (Figure 6F).

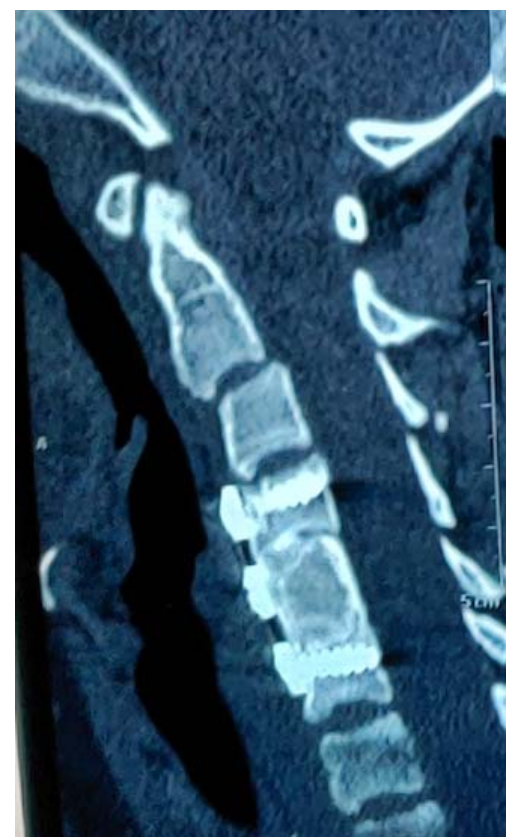

Figure 4. Sagittal computed tomography scan at 12 months postsurgery depicting solid anterior fusion.

\section{DISCUSSION}

Spinal TB is a destructive form of TB and is more common in children and young adults, especially in developing nations such as India. ${ }^{10}$ In the Indian subcontinent it is frequently misdiagnosed or missed due to a dearth of standard health care facilities, particularly in the rural population.

Though the incidence of tuberculosis in general and spinal TB in particular is much less in developed countries, it is on the rise with a majority of these patients being immigrants from endemic regions. In the United Kingdom over the 6-year period from 1999 to 2004, a total of 729 patients had TB; of these, $8 \%$ (61 cases) had musculoskeletal involvement, with 30 of them having spinal $\mathrm{TB}^{11}$. Immigrants from endemic areas such as the Indian subcontinent formed the majority of these patients. The World Health Organization data ${ }^{12-14}$ suggest an estimated incidence of 10.0 million new cases of TB in 2018, of which Southeast Asia contributed to $44 \%$ of the global load.

With the availability of effective antitubercular therapy, ${ }^{15}$ a significant proportion of spinal tuberculosis can be treated nonoperatively, principally if started in the early phase.

Surgical treatments are still needed for patients with severe kyphosis, ${ }^{16}$ increasing neurologic deficit, or refractory disease process. The purpose of this study was to show the effectiveness of surgical 

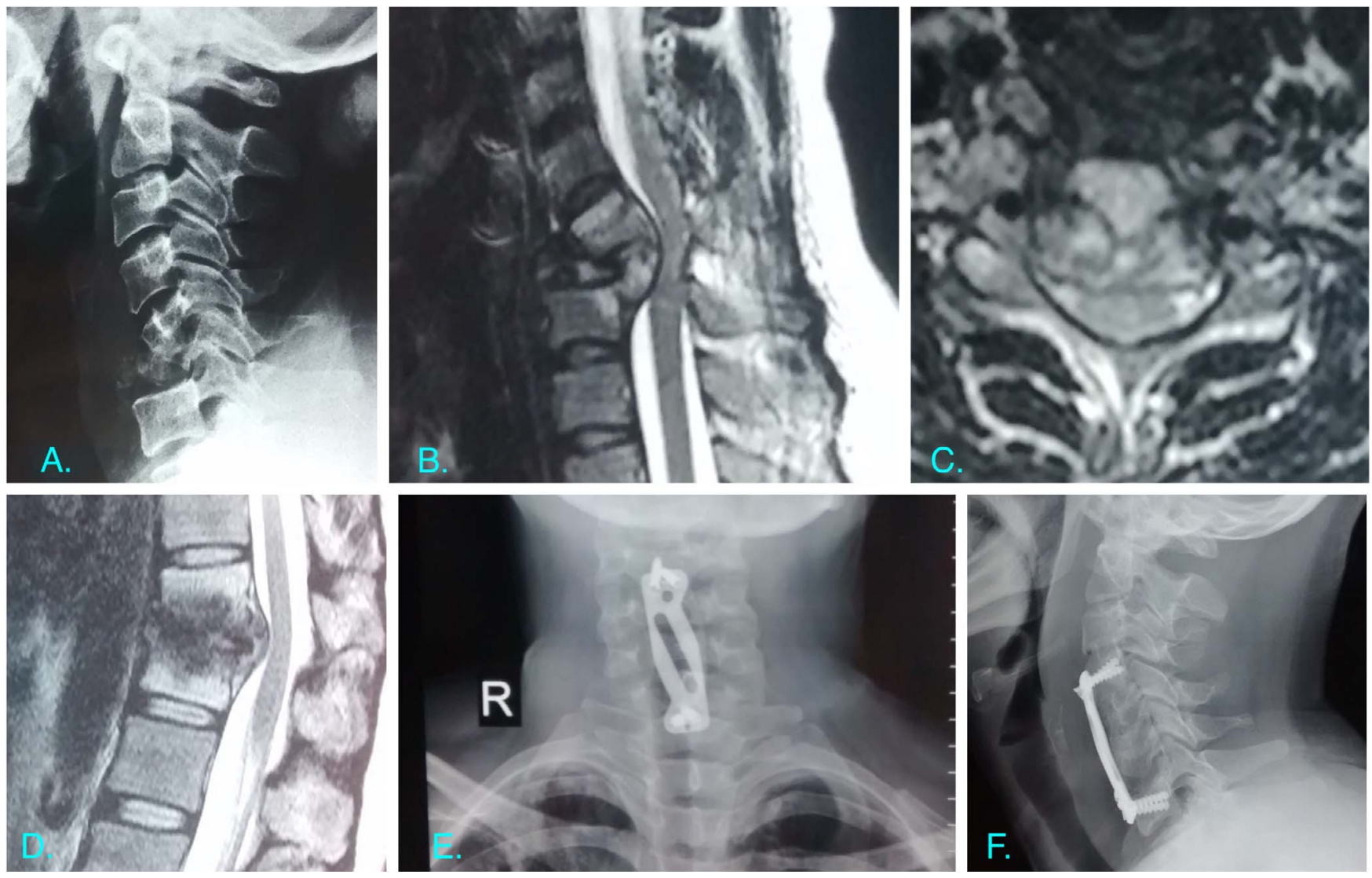

Figure 5. (A) Plain radiographs of Case Illustration 2 revealed destruction of C5 and C6 vertebral bodies. (B) T2 sagittal MRI demonstrated retropulsion of C5 and compression of the spinal cord. (C) T2 axial MRI showing severe ventral compression of the cord with loss of cerebrospinal fluid signal. (D) T2 sagittal MRI at dorsolumbar junction showing a skip lesion at D11-D12 with no cord compression. (E) Plain anterior posterior radiograph depicting anterior surgery with cervical plating. $(F)$ Lateral radiograph postsurgery demonstrating restoration of cervical lordosis.

decompression, debridement along with instrumentation, and bone grafting in cases of subaxial cervical tuberculosis. This was assessed by improvement in neurology in the postoperative period, correction of the kyphotic deformity, incidence of complications, and assessment of union.

There are reports of posterior instrumentation ${ }^{17}$ in a few cases, but anterior instrumentation is the norm accepted by surgeons the world over. Posterior instrumentation requires a dual anterior plus posterior approach, ${ }^{18}$ which adds to the perioperative morbidity. In addition, in cervical TB the vertebral body, which is an anterior structure in the vertebral column, is most often the focus of infection, and, therefore, anterior decompression and instrumentation seems to be the natural choice of procedure.

Neurological deficit is perhaps the worst complication for a patient with spinal tuberculosis. This has been reported in the literature as varying from $23 \%-76 \%{ }^{19}$ In our case series, 30 of 46 patients had some degree of neurological involvement at presentation. There was considerable improvement in the neurological status in all the patients in the case series. Mak and Cheung ${ }^{20}$ reported an improvement in $94 \%$ of their patients, all of whom were operated upon with the anterior approach. Faraj $^{21}$ noted recovery in all 3 patients operated by them having an initial Frankel grade 3 neurological status over a 2- to 6-year follow-up. Hassan et $\mathrm{al}^{22}$ reported complete recovery in $85 \%$ patients in a series of 16 patients operated by anterior debridement, fusion, and H-plate fixation. Ramani et $\mathrm{al}^{23}$ in a case series of 61 patients with subaxial TB surgically treated with anterior debridement and anterior reconstruction with fixation using titanium plate classified their findings as excellent (grade V power) in $85 \%$ cases, good (residual wasting but no functional sequelae) in $7 \%$, and fair (persistent disability) in $8 \%$. He et $\mathrm{al}^{24}$ in their study in China found 15 patients to have complete recovery at final follow-up out of 20 patients with preoperative neuro-deficit. Loembe ${ }^{25}$ reported $100 \%$ improvement in neurological status in 5 patients with 

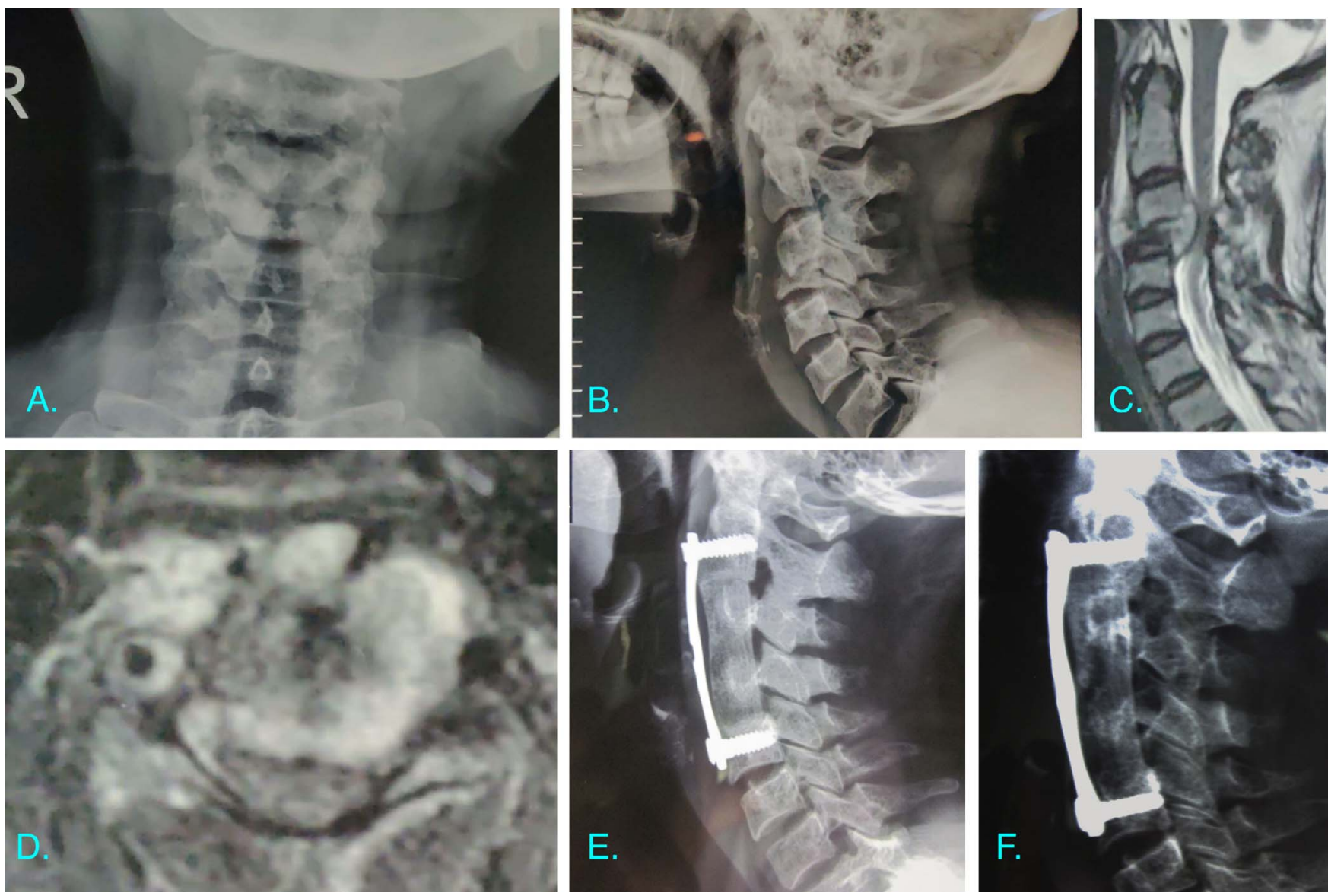

Figure 6. (A, B) Plain radiographs of Case Illustration 3 revealed destruction of C3 and C4 vertebral bodies. (C) T2 sagittal MRI demonstrated retropulsion of C3 and prevertebral and epidural soft tissue extension. (D) T2 axial MRI showing severe ventral compression of the cord more on the left side than on the right. (E) Lateral radiograph postsurgery demonstrating good cervical lordosis and reconstruction of the anterior column. (F) Lateral radiograph at 12 -month follow-up demonstrating good anterior fusion.

cervical TB who underwent operations in Gabon, Africa.

Another important indication for surgery in our case series was to prevent and correct kyphotic deformity. Preventing kyphosis also helps in avoiding late onset neurological compression and deficit. Pediatric cases have a higher rate of kyphotic deformity, and the deformity can continue to grow even after healing of the tubercular lesion. In our study the average Cobb angle was $15.4^{\circ}$ kyphosis, which after postoperative correction was found to be $17.9^{\circ}$ cervical lordosis. There was very minimal loss of correction at final follow-up. The largest deformity was of $58^{\circ}$ kyphosis in a 38 -year-old woman with tubercular involvement of the first and second dorsal vertebrae. The postoperative correction was a massive $63^{\circ}$, with the final result being lordosis of $5^{\circ}$. He et al ${ }^{24}$ in their case series measured a preoperative average kyphotic deformity of $15.48^{\circ}$ (adult: $10^{\circ}$; children: $37.4^{\circ}$ ), which improved to $-4.8^{\circ}$ postoperatively. This mean was calculated to $3.6^{\circ}$ at final follow-up. They used only intraoperative distraction and no skull traction. In patients with serious deformities, extension of the table was performed. On the other hand, in our case series intraoperative skull traction with Gardner-Wells tongs was used for every case. Hassan et $\mathrm{al}^{22}$ used skull traction in the preoperative period in all patients with a Cobb angle of more than $20^{\circ}$.

The controversy regarding surgical versus conservative management of tuberculosis of cervical spine began as early as 1960 when Konstam et al ${ }^{26,27}$ advised conservative management, whereas Hodgson et $\mathrm{al}^{28}$ advocated a primarily surgical line of treatment. Experts over the years after several trials and studies have now concluded that more than $40 \%$ patients with Pott paraplegia recover with antitubercular medication and bed rest. Various surgeries that can be performed are based on the principles of debridement of the infected material with spinal reconstruction and stabilization. Reconstruction can be done using bone graft (either 
autologous or allograft) or a cage. The stabilization is further performed using material such as titanium, steel, or carbon fiber. Reconstruction in all patients in our series was performed using autologous bone graft from the anterior superior iliac spine. There were no patients with infection of the graft site, though $5 \%$ complained of pain at the harvest site for 2-3 weeks. Various studies have shown autologous bone graft to have better osteointegration and maintenance of the sagittal column. He et $\mathrm{al}^{24}$ had similar observations with the use of autologous iliac graft with 3 patients having graft-site pain for 1 week. On the contrary, they used allograft for reconstruction of the anterior column defect in the pediatric age group. Koptan et $\mathrm{al}^{29}$ compared the outcome of iliac bone graft and titanium mesh cage for anterior reconstruction of cervical spinal lesion. They found the use of cage to have better kyphotic correction than bone graft. Other parameters were comparable in the 2 groups. In addition, according to our observations the use of an anterior plate helps in better graft incorporation.

\section{CONCLUSIONS}

Subaxial cervical $\mathrm{TB}$ is a disease known for grotesque deformities and devastating neurological involvement, especially with untreated cases. However, appropriate medical and surgical management directed at realigning the biomechanical axis provides equally good correction of deformities and provides an environment suitable for neurological recovery and sound fusion.

Our study had limitations in the form of small sample size and a single-center involvement. Further studies are required with multicentric involvement for a better understanding.

\section{REFERENCES}

1. Sternbach G. Percivall Pott: tuberculous spondylitis. $J$ Emerg Med. 1996;14(1):79-83. doi:10.1016/07364679(95)02053-5

2. Rajasekaran S, Soundararajan DCR, Shetty AP, Kanna RM. Spinal tuberculosis: current concepts. Global Spine J. 2018;8(suppl 4):S96-S108. doi:10.1177/2192568218769053

3. Sadek A-R, Wallage W, Jaiganesh T. Cervical spine tuberculosis causing instability and neurological compromise. JRSM Short Rep. 2011;2(6):47. doi: 10.1258/shorts.2011.011040

4. Tuli SM. Results of treatment of spinal tuberculosis by “middle-path" regime. J Bone Joint Surg Br. 1975;57(1):13-23.

5. Jain AK, Jain S. Instrumented stabilization in spinal tuberculosis. Int Orthop. 2012;36(2):285-292.

6. van Middendorp JJ, Goss B, Urquhart S, Atresh S,
Williams RP, Schuetz M. Diagnosis and prognosis of traumatic spinal cord injury. Global Spine J. 2011;1(1):1-8. doi:10.1055/s0031-1296049

7. Sinan T, Al-Khawari H, Ismail M, Ben-Nakhi A, Sheikh M. Spinal tuberculosis: CT and MRI feature. Ann Saudi Med. 2004;24(6):437-441. doi:10.5144/0256-4947.2004.437

8. Bruchfeld J, Correia-Neves M, Källenius G. Tuberculosis and HIV coinfection. Cold Spring Harb Perspect Med. 2015;5(7):a017871. doi:10.1101/cshperspect.a017871

9. Rahman N-U, El-Bakry A, Jamjoom A, Jamjoom ZA, Kolawole TM. Atypical forms of spinal tuberculosis: case report and review of the literature. Surg Neurol. 1999;51(6):602607. doi:10.1016/s0090-3019(98)00101-3

10. Agrawal V, Patgaonkar PR, Nagariya SP. Tuberculosis of spine. J Craniovertebr Junction Spine. 2010;1(2):74-85. doi:10.4103/0974-8237.77671

11. Ratnappuli A, Collinson S, Gaspar-García E, Richardson L, Bernard J, Macallan D. Pott's disease in twenty-first century London: spinal tuberculosis as a continuing cause of morbidity and mortality. Int $J$ Tuberc Lung Dis. 2015;19(9):1125, i-ii. doi:10.5588/ijtld.15.0091

12. World Health Organization. 2019. Global tuberculosis report. https://www.who.int/tb/publications/global_report/en/. Accessed June 30, 2020.

13. World Health Organization. 2019. Country profiles for 30 high TB burden countries. https://www.who.int/tb/ publications/global_report/tb19_Report_country_profiles_ 15October2019.pdf?ua=1. Accessed June 30, 2020.

14. World Health Organization. 2019. Regional and global profiles. https:/www.who.int/tb/publications/global_report/ tb19_Report_regional_global_15October2019.pdf?ua=1. Accessed June 30, 2020.

15. World Health Organization. Standard treatment regimens. Treatment of Tuberculosis: Guidelines. 4th ed. Geneva: World Health Organization; 2010:29-52. https://www.who.int tb/features_archive/new_treatment_guidelines_may2010/en/. Accessed December 27, 2020.

16. Rasouli MR, Mirkoohi M, Vaccaro AR, Yarandi KK, Rahimi-Movaghar V. Spinal tuberculosis: diagnosis and management. Asian Spine J. 2012;6(4):294-308. doi:10.4184/ asj.2012.6.4.294

17. Zhang HQ, Lin MZ, Guo HB, Ge L, Wu JH, Liu JY. One-stage surgical management for tuberculosis of the upper cervical spine by posterior debridement, short-segment fusion, and posterior instrumentation in children. Eur Spine $J$. 2013;22(1):72-78. doi:10.1007/s00586-012-2544-0

18. Yin XH, He BR, Liu ZK, Hao DJ. The clinical outcomes and surgical strategy for cervical spine tuberculosis: a retrospective study in 78 cases. Medicine (Baltimore). 2018;97(27):e11401. doi:10.1097/MD.0000000000011401

19. Jain AK, Kumar J. Tuberculosis of spine: neurological deficit. Eur Spine J. 2013;22(suppl 4):624-633. doi:10.1007/ s00586-012-2335-7

20. Mak KC, Cheung KM. Surgical treatment of acute TB spondylitis: indications and outcomes. Eur Spine J. 2013;22(suppl 4):603-611. doi:10.1007/s00586-012-2455-0

21. Faraj AA. Anterior instrumentation for the treatment of spinal tuberculosis [comment]. J Bone Joint Surg Am. 2001;83(3):463-464. doi:10.2106/00004623-200103000-00027

22. Hassan MG. Anterior plating for lower cervical spine tuberculosis. Int Orthop. 2003;27(2):73-77. doi:10.1007/s00264002-0400-2 
23. Ramani PS, Sharma A, Jituri S, Muzumdar DP. Anterior instrumentation for cervical spine tuberculosis: an analysis of surgical experience with 61 cases. Neurol India. 2005;53(1):83-89. doi:10.4103/0028-3886.15067

24. He M, Xu H, Zhao J, Wang Z. Anterior debridement, decompression, bone grafting, and instrumentation for lower cervical spine tuberculosis. Spine J. 2014;14(4):619-627. doi:10. 1016/j.spinee.2013.06.076

25. Loembe PM. Tuberculosis of the lower cervical spine (C3-C7) in adults: diagnostic and surgical aspects. Acta Neurochir (Wien). 1994;131(1-2):125-129. doi:10.1007/ BF01401462

26. Konstam PG, Konstam ST. Spinal tuberculosis in southern Nigeria with special reference to ambulant treatment of thoracolumbar disease. J Bone Joint Surg Br. 1958;40$\mathrm{B}(1): 26-32$.

27. Konstam PG, Blesovsky A. The ambulant treatment of spinal tuberculosis. Br J Surg. 1962;50:26-38. doi:10.1002/bjs. 18005021908

28. Garg RK, Somvanshi DS. Spinal tuberculosis: a review. J Spinal Cord Med. 2011;34(5):440-454. doi:10.1179/ 2045772311Y.0000000023

29. Koptan W, Elmiligui Y, Elsharkawi M. Single stage anterior reconstruction using titanium mesh cages in neglected kyphotic tuberculous spondylodiscitis of the cervical spine. Eur Spine J. 2011;20(2):308-313. doi:10.1007/s00586-010-1537-0

Disclosures and COI: The authors received no funding for this study and report no conflicts of interest.

Corresponding Author: Dr Aditya Raj, 6th Floor, Orthopaedics Office, New Building, KEM Hospital, Parel, Mumbai 400012, Maharashtra, India. Phone: +91-9767002886; Email: adityagmck@gmail.com.

Published 26 February 2021

This manuscript is generously published free of charge by ISASS, the International Society for the Advancement of Spine Surgery. Copyright (C) 2021 ISASS. To see more or order reprints or permissions, see http://ijssurgery.com. 